
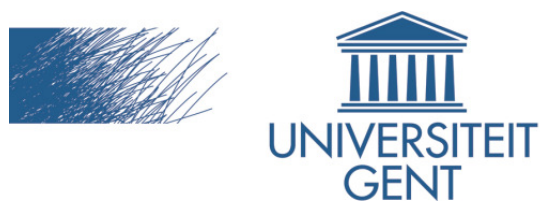

biblio.ugent.be

The UGent Institutional Repository is the electronic archiving and dissemination platform for all UGent research publications. Ghent University has implemented a mandate stipulating that all academic publications of UGent researchers should be deposited and archived in this repository. Except for items where current copyright restrictions apply, these papers are available in Open Access.

This item is the archived peer-reviewed author-version of:

Digital elevation model generation for historical landscape analysis based on LiDAR data, a case study in Flanders (Belgium)

Werbrouck, I.; Antrop, M.; Van Eetvelde, V.; Stal, C.; De Maeyer, P.; Bats, M.; Bourgeois, J.; Court-Picon, M.; Crombé, P.; De Reu, J.; De Smedt, P.; Finke, P.A.; Van Meirvenne, M.; Verniers, J.; Zwertvaegher, A.

In: Expert Systems with Applications, Vol. 38 (7), p. 8173-8185, 2011.

doi: 10/1016/j.eswa.2010.12.162

To refer to or to cite this work, please use the citation to the published version:

Werbrouck, I.; Antrop, M.; Van Eetvelde, V.; Stal, C.; De Maeyer, P.; Bats, M.; Bourgeois, J.; Court-Picon, M.; Crombé, P.; De Reu, J.; De Smedt, P.; Finke, P.A.; Van Meirvenne, M.; Verniers, J.; Zwertvaegher, A. (2011). Digital elevation model generation for historical landscape analysis based on LiDAR data, a case study in Flanders (Belgium). Expert Systems with Applications, Vol. 38 (7), p. 8173-8185. doi: 10/1016/j.eswa.2010.12.162. 


\title{
Digital elevation model generation for historical landscape analysis based on LiDAR data, a case study in Flanders (Belgium)
}

\author{
I. Werbrouck ${ }^{1}$, M. Antrop ${ }^{1}$, V. Van Eetvelde ${ }^{1}$, C. Stal ${ }^{1}, \mathrm{Ph}^{2}$ De Maeyer ${ }^{1}$, \\ M. Bats ${ }^{2}$, J. Bourgeois ${ }^{2}$, M. Court-Picon ${ }^{4}$, Ph. Crombé ${ }^{2}$, J. De Reu ${ }^{2}$, \\ Ph. De Smedt ${ }^{3}$, P.A. Finke ${ }^{4}$, M. Van Meirvenne ${ }^{3}$, J. Verniers ${ }^{4}$, A. Zwertvaegher ${ }^{4}$
}

\begin{abstract}
Keywords
Airborne LiDAR; DEM; filtering; geoarchaeology; microtopography; landscape visualization; multi-scale concept
\end{abstract}

\section{Summary}

This paper discusses the generation of a high precision DEM (Digital Elevation Model) based on high density airborne LiDAR (Light Detection and Ranging) data for an interdisciplinary landscape archaeological study concerning the settlement history and environment in Sandy Flanders, a region to the north of Ghent (Belgium). The objective was to create a detailed topographical surface free of artificial features and topographical artefacts, in the form of a DEM, visualizing the natural and current topography through the implementation of true ground points only. The semi-automatical removal of these features and artefacts was based on topographical vector data, visual interpretations and slope analysis. Ultimately two DEM's were constructed (1) a TIN (Triangulated Irregular Network) model, whereby the inherent large file format restricts the usability to large scale and (2) a grid model which can be used for small-, medium- and large-scale applications. Both datasets were used as an image that is interpreted using ancillary data from historical sources. Its usefulness is illustrated in a case of field pattern and microfield topography. Starting from this DEM, the approach of this landscape historical study is mainly retrogressive, i.e. starting from the landscape structures and elements that are still present in the contemporary landscape and moving into the past.

\section{Introduction}

Airborne LiDAR data for topographic data collection is available since the 1980s (Ackermann 1999; Drosos and Farmakis 2006; Liu 2008). This technology is frequently used in a broad range of applications, such as geomorphological research (Eeckhaut et al. 2007; Kasai et al. 2009), coastal zone monitoring (Fernandes et al. 2004; Lohr 1998; Mutlu et al. 2008; Saye et al. 2005; Utkin et al. 2002; Zhou and Xie 2009), forest fire management (Fernandes et al. 2004; Mutlu et al. 2008; Utkin et al. 2002) and infrastructural and environmental projects (Challis et al. 2008; Wehr and Lohr 1999a). More significant applications for this technology are found in archaeological surveys (Bewley et al. 2005; Carey et al. 2006; Challis 2006; Devereux et al. 2008;

\footnotetext{
${ }^{1}$ Department of Geography, Ghent University, Krijgslaan 281, 9000 Ghent, Belgium

${ }^{2}$ Department of Archaeology, Ghent University, Sint-Pietersnieuwstraat 35, 9000 Ghent, Belgium

${ }^{3}$ Department of Soil management, Ghent University, Coupure Links 653, 9000 Ghent, Belgium

${ }^{4}$ Department of Geology and Soil Science, Ghent University, Krijgslaan 281, 9000 Ghent, Belgium
} 
English_Heritage; Gallagher and Josephs 2008; Harmon et al. 2006; Powlesland et al. 2006) and to support archaeological management programs (Bewley et al. 2005).

LiDAR is an active remote sensing technique (Mutlu et al. 2008) which provides subrandomly distributed three-dimensional terrain point data (Axelsson 1999; Drosos and Farmakis 2006; Liu 2008; Lloyd and Atkinson 2005). It uses a laser pulse to measure the terrain elevation derived from the time between emission and reception of reflected pulses (Drosos and Farmakis 2006; Liu 2008; Lloyd and Atkinson 2005)). Through laser altimetry, the $\mathrm{x}-, \mathrm{y}$ - and $\mathrm{z}$-coordinates are registered. The $\mathrm{x}$ - and $\mathrm{y}$-coordinates represent the planimetric position and the z-coordinate the altimetric position (Drosos and Farmakis 2006). The final data is generally provided in a comma-delimited ASCII format (Drosos and Farmakis 2006; Liu 2008). Because only coordinates are provided and no object information is given, the interpretability of the raw data is limited (Axelsson 1999). Moreover, LiDAR data acquisition is expensive and consists of enormous volumes of data (Axelsson 1999; Challis et al. 2008; Liu 2008). However, the exceptional planimetric accuracy of centimeter level, which is the main advantage, and the regular scan pattern with high density allow the production of a high quality Digital Elevation Model (DEM) reducing data volume significantly and making the elevation data more workable (Axelsson 1999; Drosos and Farmakis 2006; Liu 2008; Lohr 1998). Because of this, airborne LiDAR is replacing gradually conventional stereophotogrammetric methods (Drosos and Farmakis 2006; Liu 2008). An additional advantage of LiDAR altimetry compared to photogrammetry is that it also penetrates vegetation, by the multiple echo characteristics and allows acquiring ground level points trough vegetation cover (Ackermann 1999; Axelsson 1999; Drosos and Farmakis 2006; Liu 2008; Wehr and Lohr 1999b; Zhou et al. 2004). In European type coniferous and deciduous forests, penetration rates of 20 till 40 percent can be expected and up to nearly 70 percent in deciduous forests in winter time (Ackermann 1999). The fast and slightly higher automated LiDAR data processing is moreover much cheaper compared to vertical aerial photography (Ackermann 1999; Axelsson 1999; Challis et al. 2008; Liu 2008). For details concerning the technical principles of LiDAR, readers are referred to Drosos and Farmakis (2006), Wehr and Lohr (1999a) and Lohr (1998).

The study area fits within the interdisciplinary landscape archaeological project concerning settlement history and environmental change in Sandy Flanders north of Ghent (Belgium). The overall goal of this project is to understand the spatial distribution of archaeological artefacts of different pre- and protohistoric periods in relation to landscape and environmental changes. Principally, the project studies how the palaeolandscape determined the occupation and land exploitation strategies, starting from the Late Glacial up until the beginning of the Roman period. This requires an interdisciplinary, landscape-orientated approach. Several research processes are carried out simultaneously by different research groups of the Ghent University, in particular Archaeology, Geography, Palaeontology, Soil Management, Geology and Soil Science. In terms of historical landscape conditions and landscape change over time, this knowledge is particularly valuable for successful landscape protection and planning (Bender 2009). Not only the historical development of the present landscape but also a reconstruction of past landscape conditions can be useful for applied historical geography (Bender 2009). In an international context, the project fits into the broader framework of 
the European treaty of La Valetta of the Council of Europe (1992) concerning archaeological heritage. The project will contribute to the development of scientific methods required for assessing the archaeological potential of areas under threat by present-day activities.

The specific objectives of this paper are twofold. Firstly, transforming airborne LiDAR data into a high precision DEM of the recent and natural surface free of artefacts for landscape historical research and secondly the use of the DEM for the study of field pattern and microfield topography.

\section{Methods and material}

\subsection{Study area}

The study area covers $1400 \mathrm{~km}^{2}$ and ranges from the city of Bruges in the west to the town of Temse in the east and stretches north of the city of Ghent to the northern state border with The Netherlands (figure 1). The area corresponds to the northern part of the Pleistocene valley of the Scheldt River, filled up with sandy, Pleistocene deposits which were remodeled during the Early Holocene (Heyse 1983). Different landscape types occur within this generally flat area, characterized by a subtle micromorphology. This variation was an important factor in the settlement history as illustrated by the discontinuous spread, both chronologically and geographically, of archaeological sites (figure 1). Important landscape types are a late glacial fossil lake, filled with peat and lake marl, cuestas of Tertiary clay outcrops, river and brook valleys, a massive dune complex and some smaller sandy ridges alternated with small depressions. Soils and environmental conditions vary with geomorphology as well.

The integrative geoarchaeological project uses three scales of analysis. The comprehensive area (zone 1 in figure 1) covers the northern part of the Pleistocene valley. This area is not only important as a context for more detailed scientific analysis, it is also valuable for heritage protection and management. According to the Flemish landscape atlas, many relics of traditional landscapes still exist here (Antrop and Eetvelde 2007). The meso-level (zone 2 in figure 1) covers the hydrographical basin to which the smaller depression of zone 3 belongs. On this mesoscale spatial modelling of the development of the hydrographical network and a land evaluation related to the archaeological sites is performed. This zone contains heritage landscapes that are subject to spatial planning procedures according to the implementation of the European Landscape Convention (Antrop and Eetvelde 2007). The microscale corresponds to a former late glacial lake and lake environment where peat was formed, which was an important natural resource during history (zone 3 in figure 1). The morphogenesis of this marshy depression is not well known yet. On this micro-level all research teams work together using different approaches and the most detailed data sources and intensive field work. 


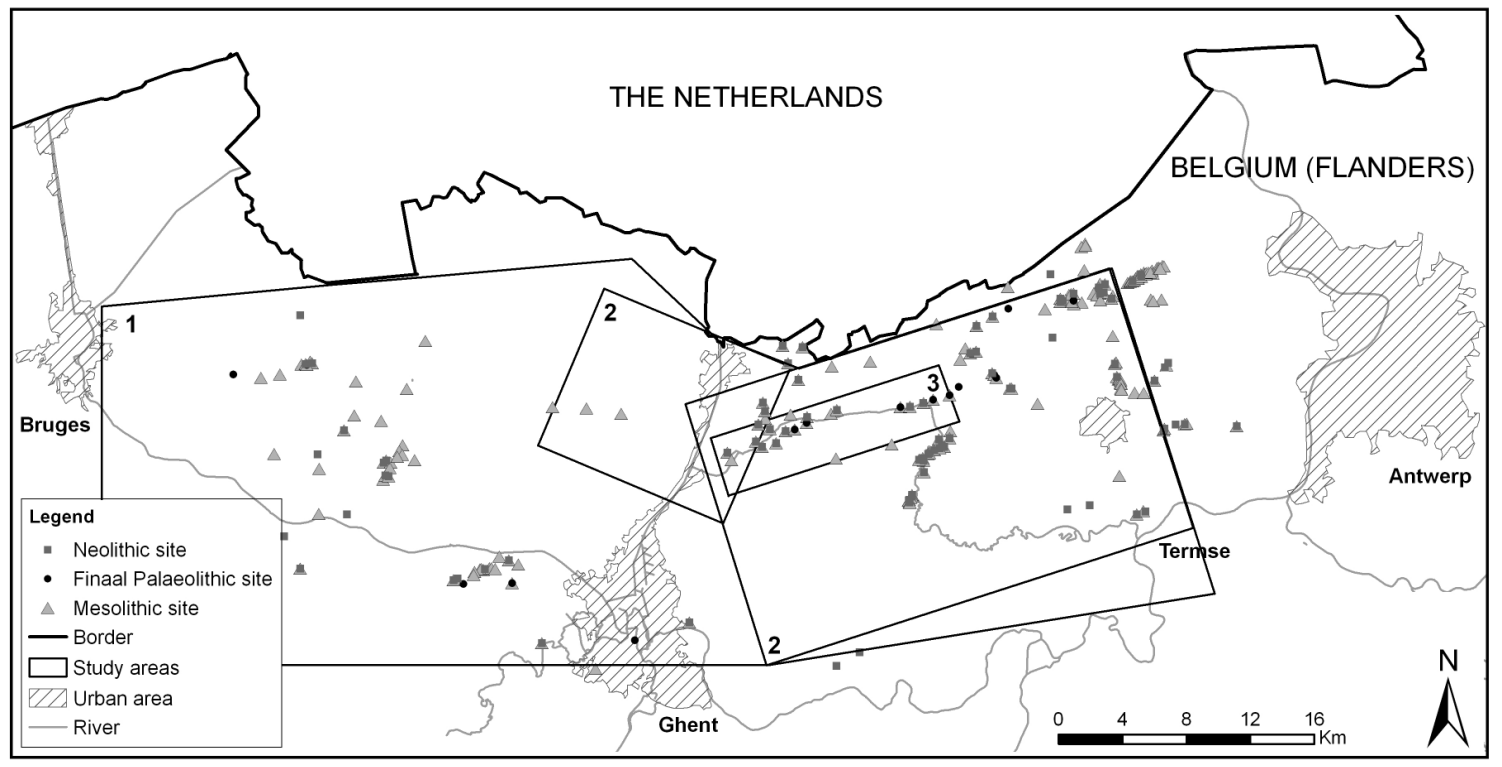

Figure 1: The landscape archaeological project. 1: study area macroscale, 2: mesoscale, 3: microscale. Known archaeological sites are indicated.

\subsection{LiDAR data and DEM generation}

The high precision airborne LiDAR measurements are distributed by the Flemish GIS Agency (AGIV) and were obtained for the entire macro-scale study area (zone 1 in figure 1). The data is registered between 2001 - 2004 in the scope of integral water management. They consist of flight strips with swath widths varying between 350 and 750 meters and a sample density of at least 1 point/4 $\mathrm{m}^{2}$ (AGIV 2003) and an average density of 1 point $/ 2 \mathrm{~m}^{2}$. The altimetric accuracy ranges from $7 \mathrm{~cm}$ on a concrete surface to $20 \mathrm{~cm}$ on vegetation cover (AGIV 2003), which is significantly better than the planimetric accuracy with a typical value in the order of $50 \mathrm{~cm}$ (Drosos and Farmakis 2006). However, for less detailed and more common applications, the data is available in a more standard and practical grid format with a cell size of 5, 25 or 100 meters generalized trough Inverse Distant Weighting. The technical background information is summarized in table 1 .

Tabel 1: Technical background information of LiDAR data

$\begin{array}{ll}\text { survey data } & 2001-2004 * \\ \text { co-ordinate system } & \text { Lambert BD - 72/50* } \\ \text { altimetric accuracy } & 7-20 \mathrm{~cm} * \\ \text { planimetric accuracy } & 50 \mathrm{~cm} * * \\ \text { minimum sample density } & 1 \text { point / } 4 \mathrm{~m}^{2} * \\ \begin{array}{l}\text { average sample density } \\ \multicolumn{2}{c}{\text { * AGIV 2003; ** Drosos and Farmakis } 2006}\end{array}\end{array}$


The original format of the LiDAR data are xyz ASCII files containing data points representing not only terrain elevation but also topographical objects like vegetation and buildings as well as current disturbances of the natural topography by artificial features like road banks, waste dumps, lakes and ponds. These data is filtered before delivery to obtain two separate data sets: one of the ground level points and one representing the height of topographical objects like vegetation and buildings (AGIV 2003) (figure 2). It is not the purpose of this paper to give a comprehensive overview of the various filter methods but summarizing, it can be stated that these processes are based on the significant differences in height values between immediate surrounding data points (Crutchley 2009). This filtering however is the most critical and difficult step in LiDAR data processing (Liu 2008), as it creates filtering artefacts and some topographical artefacts still remain. Also, the additional artificial features, such as road banks and waste dumps, are not subject to the previously mentioned filter method. For the objectives of the research project, such as spatial modelling of pedogenesis and hydrology, landscape reconstruction and historical landscape analysis, a DEM is needed exclusively representing the natural ground level points. Therefore it is crucial to conduct a further filtering of the LiDAR ground points data to remove the topographical artefacts and artificial features. For understanding the procedure used here it is necessary to consider the concept of the DEM.

In this paper the term DEM is used as described by (Burrough 1986) in the context of "any digital representation of the continuous variation of the relief over space". Three formats of digital models are frequently used and all possess different characteristics in storage efficiency and accuracy in representing the relief. Grid Digital Elevation Models (GDEMs) represent the relief as a two-dimensional regular grid whereby each grid cell contains one elevation value. This format is the simplest and most efficient in terms of storage. Consequently it allows easy manipulation but is relatively poor in representing the relief. Contour lines are the least efficient to store and manipulate data but give the best representation of the landforms. Triangulated Irregular Networks (TINs) represent the surface by a set of contiguous and non-overlapping triangles connecting the original data points. They have quality properties between GDEM and contour lines (Ramirez 2006).

The generation of a DEM that can be used on all scale levels is elaborated in five steps (figure 2). In the first step a GDEM is created based on the ground level points of the LiDAR data (data set 2). This GDEM is applied to produce a filtering mask, used to filter the original LiDAR data from topographical artefacts and artificial features (step 2). Step 3 contains the filling of the empty areas resulting from the masking procedure. This final LiDAR dataset 4 is used to create the final DEM representing only true ground points. Given the applications of this DEM on different scale levels, two models are derived to visualize the natural and recent topographical surface. First, a TIN model is created to be used at a large scale of analysis only (step 4). Secondly a grid model is produced which can be used for small- and large-scale applications (step 5). 


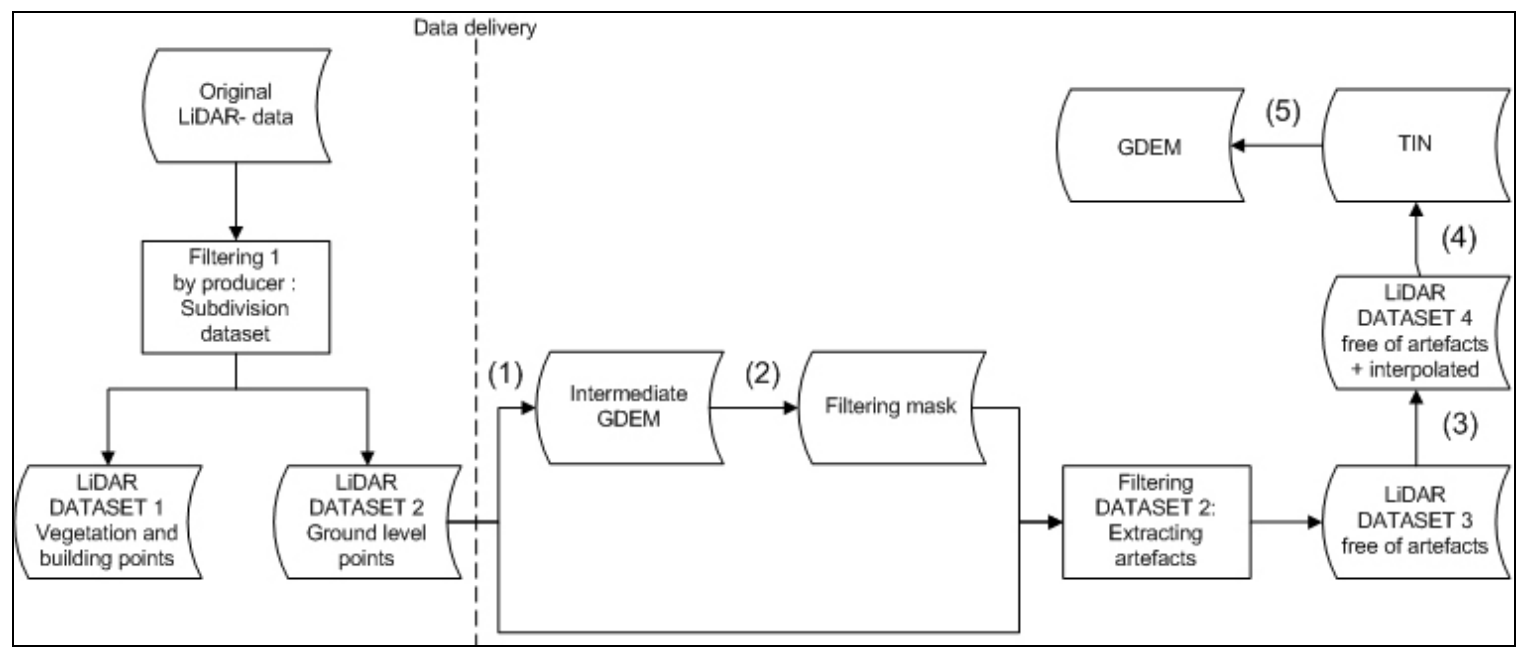

Figure 2: The different steps during DEM generation visualizing the natural and current topographical surface, steps (1) to (5) are explained in the text.

\subsubsection{Step (1)}

As the huge amount of LiDAR data is difficult to manipulate for filtering, an intermediate GDEM is prepared. Given that a higher ground resolution results in an increasing ability of recording features as well as in obtaining larger datasets, a resolution of $2 \times 2$ meters is chosen in order to obtain an optimal combination of efficiency on the one hand and precision and accuracy of terrain representation on the other hand. The high density of LiDAR data allows such a small grid size (Liu 2008) that GDEM's derived from it are most generally used (Ackermann 1999; Kraus and Otepka 2005; Liu 2008; Lohr 1998; Wack and Wimmer 2002). A TIN format is more used for large-scale areas because of the time consuming calculations (Kraus and Otepka 2005). The generation of a GDEM requires an interpolation of the irregular-spaced LiDAR points to a regular grid (Ackermann 1999; Axelsson 1999; Liu 2008; Lloyd and Atkinson 2005; Wehr and Lohr 1999a, b). Despite extensive research and a variety of empirical work conducted by numerous authors (Liu 2008), there seems to be no preferable interpolation method for GDEM generation (Fisher and Tate 2006). Like several other authors (Axelsson 1999; Drosos and Farmakis 2006), a linear interpolation method is used, based on a TIN, giving the most accurate and mathematically precise result.

\subsubsection{Step (2)}

The method to extract the artificial features and topographical artefacts is visualized in figure 3. It consists of three filtering steps, starting with a first filtering based on the automatical creation of a mask using topographical vector-data. According to Liu (2008) "the use of additional information has the potential for increasing the accuracy and reliability of the filtering process". The topographical vector data chosen was surveyed at a date as close as possible to the acquisition date of the LiDAR data. Specific distance buffers are defined around these objects and used as a mask (figure 3 (i)). For example, a railway has a buffer of 11 meters and a small road a buffer of 7 meters. The buffer size is based on a detailed analysis of the GDEM and the vector data. Given the amount and density of the artificial features and topographical artefacts to be filtered, it is 
recommended to use an automatical method at first. As no automated filter procedure is completely accurate, additional manual filtering is necessary as proposed by (Chen 2007) (figure 3 (ii)). Some topographical artefacts and artificial features are not included in the automatically created mask because of an insufficient buffer distance or the small time gap between the LiDAR survey and the topographical survey on which the mask is based. To enhance the interpretation during this second manual filtering, the GDEM is visualized on screen and treated as an image. The topographical artefacts and artificial features are visualized maximally by histogram stretching and are traceable by high contrast differences in z-values as visible on figure 3 (see arrow). In addition, this visualization is compared with aerial photographs and soil maps. A third and last filtering aims to extract small artificial elements in the GDEM, such as small drainage ditches and remnants of former ditches bordering fields. These remaining features are too small and too numerous to be removed manually during the second filtering. This third filtering implies a slope analysis followed by a removal of the elevation values for which the rate of the maximum change in $\mathrm{z}$-value in a predefined radius of surrounding cells exceeds a defined threshold (figure 3 (iii)). To avoid the removal of natural slopes, certain confined regions in the study area, exposing natural inclines exceeding this threshold, are assigned a higher threshold. Finally an overlay of the LiDAR data set 2 with this final mask based on the three filtering steps is made. Hereby the original LiDAR ground points representing topographical artefacts and artificial features are removed, leaving only true ground points.

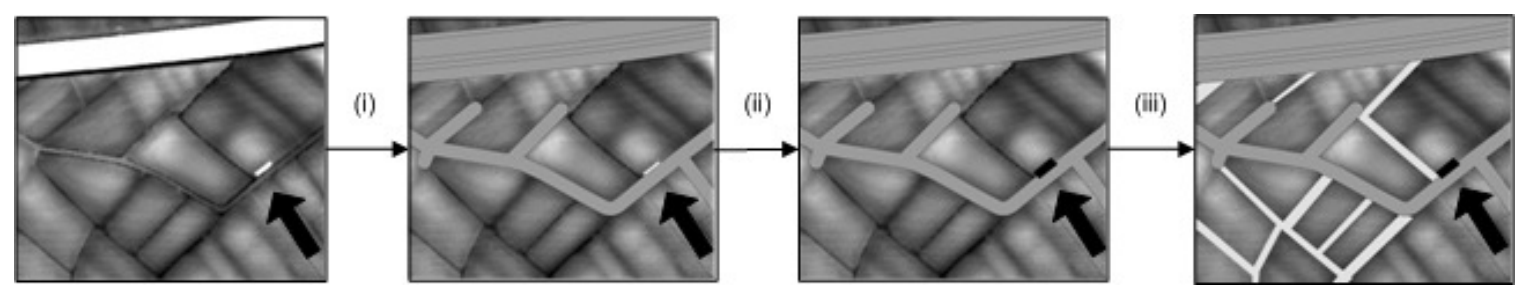

Figure 3: The different filtering steps during the removal of LiDAR points corresponding to artificial features and topographical artefacts: (i) creation of the automatic mask using topographical vector data, (ii) manual checking of the mask and manually adjusting when necessary, (iii) automatical filtering of ditches and field borders by slope analysis.

\subsubsection{Step (3)}

The filtering resulted in masked areas, where new elevation values are created through interpolation using two different methods. Small confined areas are interpolated using surrounding data points with a linear interpolation based on a TIN. The elevation for large areas is estimated based on contour lines on historical topographical maps of 1863 showing the landscape before the greater part of infrastructures was created.

\subsubsection{Step (4)}

In the fourth step, a TIN-elevation model based on the filtered LiDAR dataset 4 is created (figure 3). Unlike the grid format, the original z-values are used which results in a more accurate modelling of the land surface. The TIN model fits triangular polygons to land facets and calculates automatically slope angle and slope orientation for each triangle. To visualize the TIN, the z-values are classified into nine classes using the equal interval 
method. Visualization is achieved by a hill shade model that enhances the micromorphology. However, the TIN still reflects the sampling pattern of the LiDAR, which for example is unable to acquire data for water surfaces and results in a final form of artefacts. It concerns unnatural effects that are related to the shape and size of the triangles, affecting the visual impression. The filtering of incorrect data points from step (2) also results in similar visual effects. Therefore the model is interpreted as an image using ancillary data, such as historical map sources. Taking into account the difficulties inherent to the large datasets of this format, the study area is subdivided into a set of smaller TIN's covering $1 \mathrm{~km}^{2}$ resulting in an optimal usability for large-scale applications (figure 4). To meet the edge effect created by this subdivision an extra border of 100 meters is created, resulting in an overlap between adjacent TIN's.

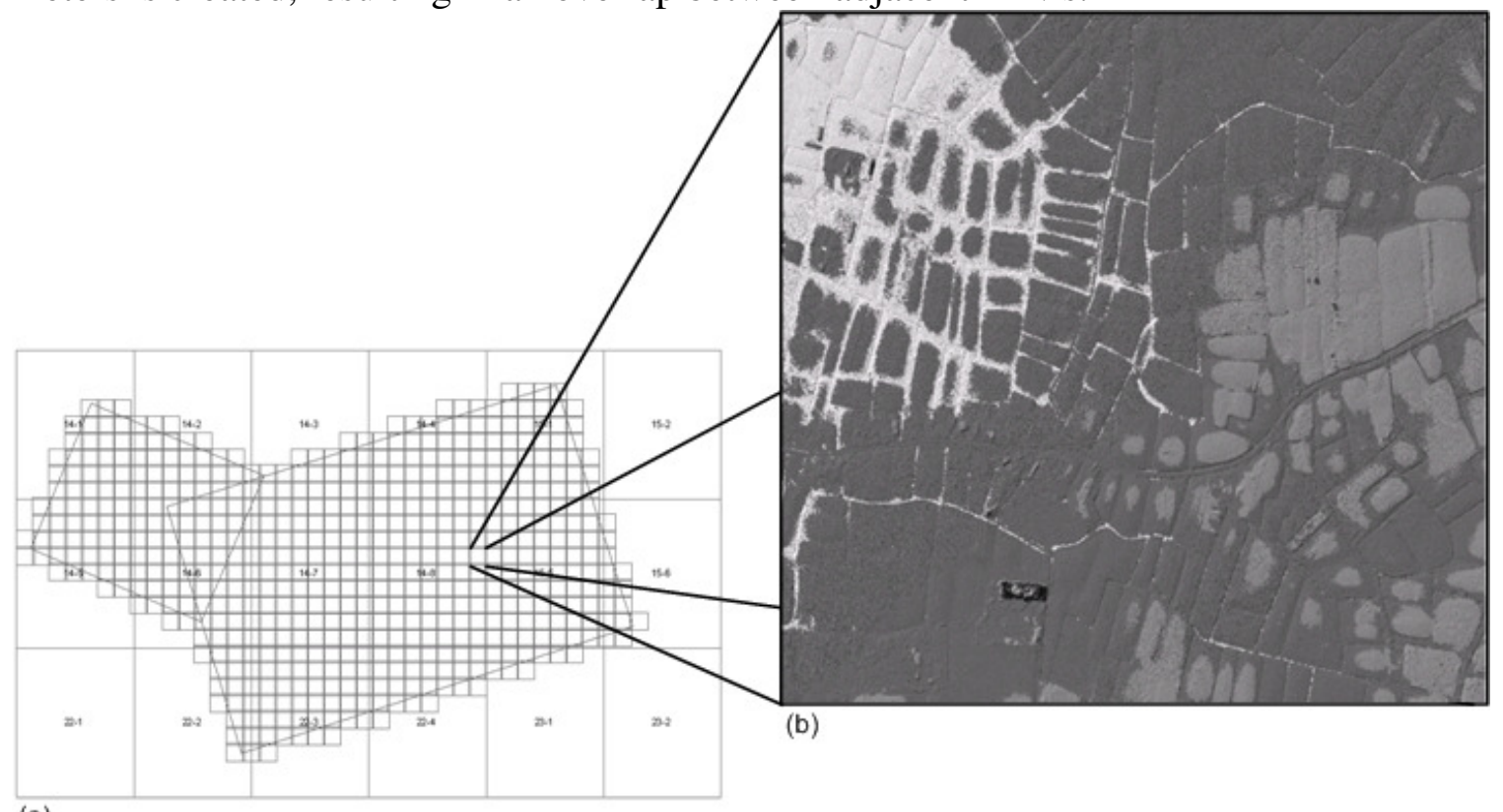

(a)

Figure 4: (a): Subdivision of the meso-scale study area into a mosaic of TIN's of $1 \mathrm{~km}^{2}$. (b): Extract of the TIN elevation model derived from LiDAR data. Elevation ranges from 2,7 meters to 12,8 meters in this frame. Hill shading is used to enhance microtopography. Three elevation land zones can be recognized and reveal the microtopography: the low lying flat area of the reclaimed marshland with ditches (light gray), the sloping border (dark gray) and the convex fields on the plateau (medium gray).

\subsubsection{Step (5)}

Additionally a GDEM with a cell size of $2 \times 2$ meters is created, using exclusively the corrected LiDAR data points and the converted contour lines. Given that a TIN carries already implicitly the approximate elevations of all points inside the triangles (Ramirez 2006), the transformation of the randomly distributed data points to a GDEM is based on the previously prepared TIN. The high density of the LiDAR data points makes it possible to define grid cells of $2 \times 2$ meters. The dataset of a GDEM is much smaller than a TIN format, which allows small-, medium- and large-scale applications. Consequently, the GDEM permits a general overview of the study area. The dataset however, is also divided into a set of smaller grids of $1,44 \mathrm{~km}^{2}$, in analogy with the TIN model (figure 5). 
This subdivision meets the limitations of a monitor which can only cover a range of 0 255 grey levels. Given the overall difference in elevation values of 61 meters, this results in a visualization of z-values in steps of 0,24 meters. The vertical accuracy of the source data however, lies in the range of centimetres resulting in an important loss of information during visualization. Subdivision into smaller areas brings along a significant decline of elevation range which leads to a better visualization of the topography.

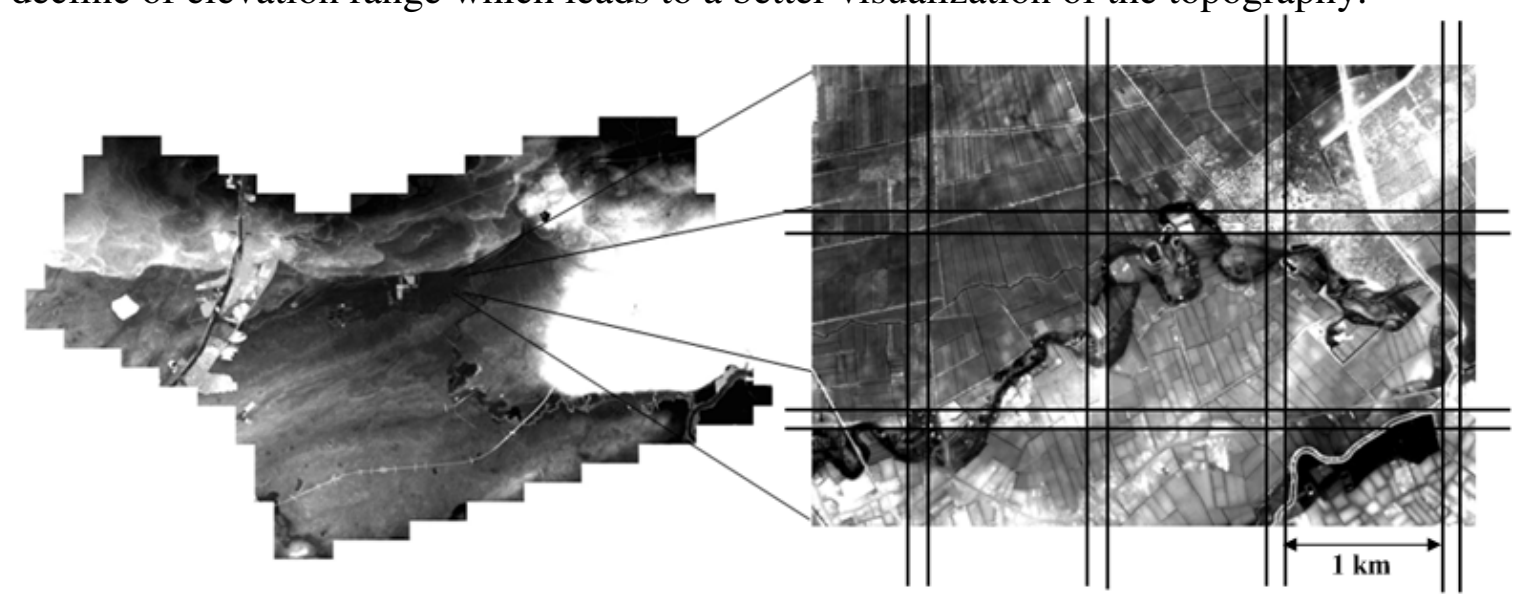

Figure 5: Grid Digital Elevation Model (GDEM) of the meso-scale study area with cell size of $2 \times 2$ meters. Elevation varies from $-10 \mathrm{~m}$ to $51 \mathrm{~m}$ shown in 256 grayscale classes (dark is low; light is high).

\section{Results and discussion}

\subsection{Interactive visualization of GDEMs}

A GDEM is not a static dataset. It can be manipulated to extract and visualize various types of information of the terrain surface. This can be done interactively. For example as represented in figure 5, the subdivision of the GDEM into $1 \mathrm{~km}^{2}$ cells allows optimal visualization of the local range of z-values. Within these cells, local microtopography can be enhanced by a histogram stretch performed by spreading the presentation of the concerning height values over the 256 grey levels a monitor displays. This range of 256 gray levels is however perceived by the human eye as a continuous gradation. When it should be possible to discriminate between z-values visualized in the GDEM, not more then 10 gray levels should be used to represent the elevation within the display. Given this limitation of the human eye in distinguishing a rather restricted amount of colors, additional aids can help the interpreter to differentiate between small-scale variations of the microtopography, for example hill shading by illumination or histogram stretching of the GDEM image. Especially the ability to exaggerate the z-values is most useful taken into account the possible enhancement of artefacts. To help interpret features and minimize the chances of features being hidden due to excessive shadow or parallel alignment to the light source, it is advisable to create images lit at a minimum of four different angles (Crutchley 2009). GDEMs also offer the possibility to derive three dimensional images, contour lines, cross sections, slope models and volume calculations. 
3.2 Integrating DEM's with historical maps and archaeological data

Two examples of results will be discussed here. Figure 6 shows an overlay of the historical map of 1909 which is the topographical reference at scale 1: 20.000 just before the First World War, combined with an enhanced image of the TIN elevation model. The area shows a small elevation up to six meter high (see contour lines), surrounded by roads, some even sunken roads. Clearly roads and houses are situated at the edge of the small bulge. The TIN clearly shows the microtopography with small depressions in the bulge. Also the field structure and field borders formed by hedge and tree rows follow the natural microtopography. Many fields have an artificial convex topography created by raising the central parts, caused by digging drainage ditches around them and circular ploughing to the center. This field type was first reported by (Snacken 1961) and archaeologically investigated by (Hove 1997). Several comparable examples are showing the possibility for detailed interpretation of the natural conditions and the human response during the creation of the landscape.

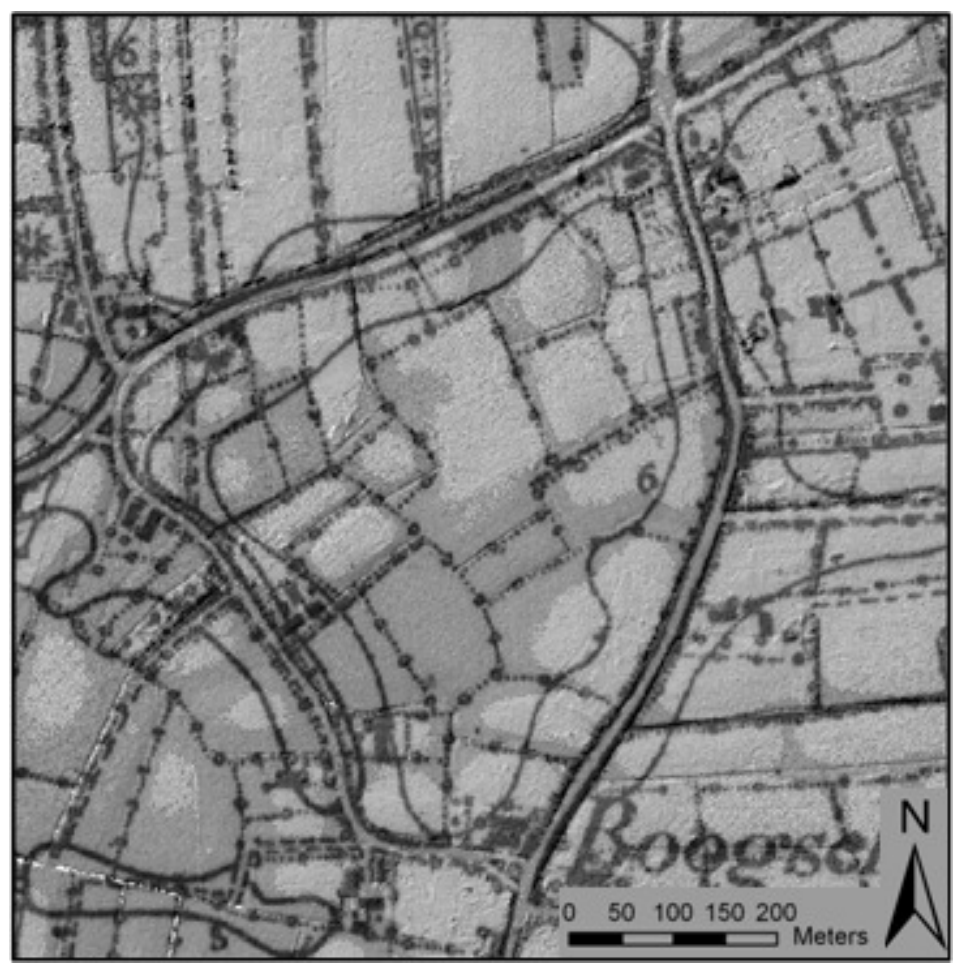

Figure 6: Overlay of a historical map of 1909 (Military Cartographic Institute) with the enhanced TIN visualized as a hill shade elevation model. Elevation varies from 5,2 $\mathrm{m}$ to $7,0 \mathrm{~m}$.

The second example illustrates how the GDEM can be used to detect archaeological and palaeoenvironmental features such as palaeochannels or filled ditches (figure 7). The grid elevation model shows in the centre an irregular depression (dark grey), some 0,3 meter lower than the surrounding grounds (light grey-white). A channel structure is marked in the middle. This pattern represents a north-south orientated palaeochannel or filled ditch which clearly can be traced in the GDEM over a distance of 2,5 kilometers. Other data 
sources (figure 7: nrs. $2-7$ ) give no evidence at all of this feature. These findings made a more purposive localization of auger transections for geophysical, palaeoecological, geomorphological and archaeological survey possible.

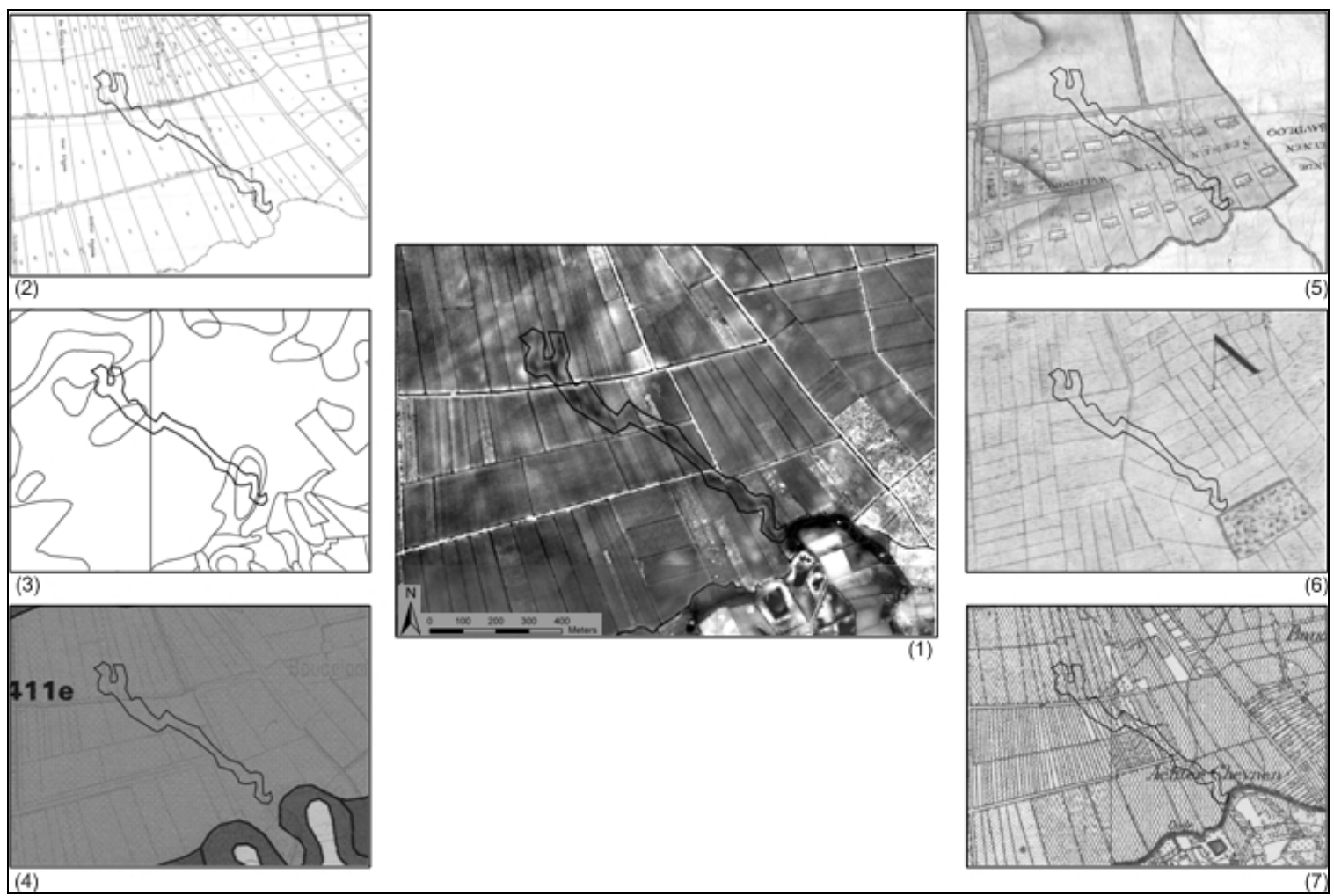

Figure 7: Composite of the GDEM with thematic and historical maps. (1) GDEM 2004, (2) Cadastral map of 1576, (3) Soil map of 1960, (4) Geomorphological map of 1999, (5) historical map of 1576, (6) historical map of 1775 and (7) historical map of 1910.

Assembling the GDEM and the TIN with historical maps and archaeological data forms the basis of further spatio-temporal landscape change analysis of the study area.

\section{Conclusions}

The aim of this paper was to generate a high precision DEM, representing the natural and recent topography and to review the possibilities of this DEM for historical geographical purpose. Trough the collection of elevation points at a much higher density than traditional survey methods, high density airborne LiDAR data forms the basis for this high quality DEM, meanwhile reducing data volume and increasing efficiency. As only true ground points should be implemented, three filtering steps were performed starting with an automatic removal based on topographical vector data followed by further manual processing by visual interpretations and an automatic filtering using slope analysis. Where artificial features and artefacts were extracted, ground heights were predicted based on a linear interpolation method using surrounding data points and historical topographical maps of 1863. Based on this set of filtered LiDAR data two different models were created. At first, a TIN is derived, which is used for large-scale 
applications and results in the best fitting to the terrain. The second model created is the GDEM with a pixel size of 2 by 2 meter, being most efficient in terms of storage and manipulation. This grid will be used for small-, medium- and large-scale applications. Both DEM models represent the natural topography free of artefacts caused by modern objects and infrastructures created since the $19^{\text {th }}$ century. Despite the considerable expenses for data acquisition and enormous volume of data, LiDAR is highly recommended for terrain visualization trough DEM generation. LiDAR derived DEMs offer the opportunity to study the earth's topography in such a high resolution which no other survey and data source can deliver for similar small-scale research. Although it is a semi-continuous model of a continuously variable being the terrain surface, it is a valuable complementary source for historical landscape research providing valuable, unique and high resolution information. The analysis of LiDAR derived DEMs requires a similar approach as aerial photographs interpretation. The interpretation of LiDAR based DEMs depends highly on the visualization technique and the resolution and should be manipulated interactive in order to detect small topographical details, for example trough hill shading. Within the scope of this interdisciplinary project the results of the DEM generation will be integrated with the outcome of the research of the natural sciences and the archaeological team with the aim of relating the settlement history and the main land use changes to natural environmental conditions and the changes of landscape ecological processes.

There can be concluded that the optimal use of LiDAR data demands multi-scale processing and the use of both grid and TIN-formats. LiDAR derived DEMs allow a more detailed landscape analysis of microtopography, field-, settlement- and road patterns and become a common reference data layer for various disciplines.

\section{Acknowledgements}

The realization of this project, especially the acquisition of the expensive LiDAR data would not be possible without the funding outgoing from the University of Ghent. More information about the project can be found on http://cartogis.ugent.be/sandy_flanders/. Also our special thanks to the Belgian agency AGIV (Agentschap voor Geografische Informatie Vlaanderen) and NGI (Nationaal Geografisch Instituut) whose willing cooperation in assembling various source materials was essential. The authors also want to thank Msc. Iason Jongepier for the acquisition of historical documents and Dr. Prof. A. De Wulf for the technical support concerning the processing of LiDAR data.

\section{References}

Ackermann, F. (1999). Airborne laser scanning-present status and future expectations. ISPRS Journal of Photogrammetry and Remote Sensing, 54, 64-67.

AGIV. (2003). Digitaal Hoogtemodel Vlaanderen. (Eds.), Nieuwsbrief GIS Vlaanderen (pp. 3-21).

Antrop, M. \& Eetvelde, V. V. (2007). L'atlas des paysages flamands dans la politique intégrée d'aménagement dut territoire. In: Berlan-Darqué, M., Luginbühl, Y. \& Terrasson, D. (Eds.), Paysages : de la connaissance à l'action. Editions Qua, c/o Inra, Collection Update Sciences \& Technologies (pp. 139-148). Versailles. 
Axelsson, P. (1999). Processing of laser scanner data - algorithms and applications. ISPRS Journal of Photogrammetry and Remote Sensing, 54, 138-147.

Bender, O. (2009). The concept of a historic landscape analysis using GIS with focus on Central Europe. In: Bender, O., Evelpidou, N., Krek, A. \& Vassilopoulos, A. (Eds.), Geoinformation Technologies for Geocultural Landscapes, European perspectives (pp. 129-144). London.

Bewley, R. H., Crutchley, S. R. \& Shell, C. A. (2005). New light on an ancient landscape; lidar survey in the Stonehenge World Heritage Site. Antiquity, 79, 636-647.

Burrough, P. A. (1986). Principles of Geographical Information Systems for Land Resources Assessment. New York: Oxford University Press

Carey, C., Brown, T., Challis, K., Howard, A. \& Cooper, L. (2006). Predictive Modelling of Multiperiod Geoarchaeological Resources at a River Confluence: a Case Study from the Trent- Soar, UK. Archaeological Prospection, 13, 241-250.

Challis, K. (2006). Airborne Laser Altimetry in Alluviated Landscapes. Archaeological Prospection, 13, 103-127.

Challis, K., Kokalj, Z., Kincey, M., Moscrop, D. \& Howard, A. J. (2008). Airhorne lidar and historic environment. Antiquity, 82, 1055-1064.

Chen, Q. (2007). Airborne LiDAR data processing and information extraction. Photogrammetric Engineering and Remote Sensing, 73, 109-112.

Crutchley, S. (2009). Shedding light on the past: Using airborne LIDAR to understand ancient landscapes. In: Bender, O., Evelpidou, N., Krek, A. \& Vassilopoulos, A. (Eds.), Geoinformation Technologies for Geocultural Landscapes, European perspectives (pp. 87-106). London.

Devereux, B., Amable, G. \& Crow, P. (2008). Visualization of LiDAR terrain models for archaeological feature detection. Antiquity, 82, 470-479.

Drosos, V. \& Farmakis, D. (2006). Airborne Laser Scanning and DTM Generation. In: Manolas, E. (Eds.), Naxos International Conference on Sustainable Management and Development of Mountainous and Island Areas (pp. 206-218). Greece.

Eeckhaut, M. V. D., Verstraeten, G. \& Poesen, J. (2007). Morphology and internal structure of a dormant landslide in a hilly area: the Collinabos landslide (Belgium). Geomorphology, 89, 258-273.

English_Heritage http://www.english-heritage.org.uk/server/show/nav.8730.

Fernandes, A. M., Utkin, A. B., Lavrov, A. V. \& Vilar, R. M. (2004). Development of neural network committee machines for automatic forest detection using lidar. Pattern recognition, 37, 2039-2047. 
Fisher, P. F. \& Tate, N. J. (2006). Causes and consequences of error in digital elevation models. Progress in Physical Geography, 30, 467-489.

Gallagher, J. \& Josephs, R. (2008). Using LiDAR to Detect Cultural Resources in a Forested Environment: an Example from Isle Royale National Park, Michigan, USA. Archaeological Prospection, 15, 187-206.

Harmon, J. M., Leone, M. P., Prince, S. D. \& Snyder, M. (2006). Lidar for Archaeological Landscape Analysis: A Case Study of Two Eighteenth-Century Maryland Plantation sites. American Antiquity, 71, 649-670.

Heyse, I. (1983). Preliminary results of the study of a vistulian late glacial drainage pattern in the scheldtbassin (Belgium - Flemish Valley - Moervaart depression). Quaternary studies in Poland, 4, 135-143.

Hove, R. V. (1997). De "klassieke” bolle akkers van het Waasland in archeologisch perspectief. Sint-Niklaas.

Kasai, M., Ikeda, M., Asahina, T. \& Fujisawa, K. (2009). LiDAR-derived DEM evaluation of deep-seated landslides in a steep and rocky region of Japan, LiDAR-derived DEM evaluation of deep-seated landslides in a steep and rocky region of Japan. Geomorphology, 113, 57-69.

Kraus, K. \& Otepka, J. (2005). DTM modelling and visualization - the SCOP approach. Photogrammetric Week 05 Wichmann Verlag, 241-252.

Liu, X. (2008). Airborne LiDAR for DEM generation: some critical issues. Progress in Physical Geography, 32, 31-49.

Lloyd, C. D. \& Atkinson, P. M. (2005). Deriving ground surface digital elevation models from LiDAR data with geostatistics. International Journal of Geographical Information Science, 20, 535-563.

Lohr, U. (1998). Digital elevation models by laser scanning. Photogrammetric Record, 16, 105-109.

Mutlu, M., Popescu, S. C. \& Zhao, K. (2008). Sensitivity analysis of fire behavior modeling with LIDAR-derived surface fuel maps. Forest Ecology and Management, 256, 289-294.

Powlesland, D., Lyall, J., Hopkinson, G., Donoghue, D., Beck, M., Harte, A. \& Stott, D. (2006). Beneath the Sand - Remote Sensing, Archaeology, Aggregates and Sustainability: a Case Study from Heslerton, the Vale of Pickering, North Yorkshire, UK. Archaeological Prospection, 13, 291-299.

Ramirez, J. R. (2006). A new approach to relief representation. Surveying and Land Information Science, 66, 19-25. 
Saye, S. E., Wal, D. v. d., Pye, K. \& Blott, S. J. (2005). Beach-dune morphological relationships and erosion/accretion: An investigation at five sites in England and Wales using LIDAR data. Geomorphology, 72, 128-155.

Snacken, F. (1961). Streekindeling en begrenzing van het Land van Waas. Belgisch Tijdschrift van de Vereniging voor Aardrijkskundige Studies, 30, 217-255.

Utkin, A. B., Lavrov, A. V., Costa, L., Simoes, F. \& Vilar, R. (2002). Detection of small forest fires by LIDAR. Applied Physics, 74, 77-83.

Wack, R. \& Wimmer, A. (2002). Digital terrain models from airborne laser scanner data - a grid based approach. International Archives of Photogrammetry, Remote Sensing and Spatial Information Sciences, 34, 293-296.

Wehr, U. \& Lohr, U. (1999a). Airborne laser scanning - an introduction and overview. ISPRS Journal of Photogrammetry and Remote Sensing, 54, 68-82.

Wehr, U. \& Lohr, U. (1999b). Theme issue on airborne laser scanning. ISPRS Journal of Photogrammetry and Remote Sensing, 54, 61-63.

Zhou, G., Song, C., Simmers, J. \& Cheng, P. (2004). Urban 3D GIS From LiDAR and digital aerial images. Computers \& Geosciences, 30, 345-353.

Zhou, G. \& Xie, M. (2009). Coastal 3-D Morphological Change Analysis Using LiDAR Series Data: A Case Study of Assateague Island National Seashore. Journal of coastal research, 25, 435-447. 